\title{
Evolutions of molecular oxygen formation and sodium migration in Xe ion irradiated borosilicate glasses \\ L. Chen ${ }^{\text {a, b, * }}$, D.F. Zhang ${ }^{\text {a, b }}$, P. Lv ${ }^{\text {a, b }}$, J.D. Zhang ${ }^{\text {a, b, c }}$, X. Du ${ }^{\text {a, b }}$, W. Yuan ${ }^{\text {a, b }}$, S. Nan ${ }^{\text {a, b }}$, Z.H. $\mathrm{Zhu}^{\mathrm{c}}$, T.S. Wang ${ }^{\mathrm{a}, \mathrm{b}}$ \\ ${ }^{a}$ School of Nuclear Science and Technology, Lanzhou University, Lanzhou 730000, China \\ ${ }^{b}$ Key Laboratory of Special Function Materials and Structure Design Ministry of Education, Lanzhou University, Lanzhou, 730000, China \\ ${ }^{c}$ Environmental Molecular Sciences Laboratory, Pacific Northwest National Laboratory, Richland, WA 99352, USA
}

\section{Abstract}

The modifications of a commercial borosilicate glass induced by Xe ion irradiation have been studied by Raman spectroscopy and ToF-SIMS depth profiling. A decrease in the average $\mathrm{Si}-\mathrm{O}-\mathrm{Si}$ angle, an increase in the population of three-membered rings and an increase of the glass polymerization are evidenced. The molecular oxygen appears in the irradiated glasses after the irradiation fluence reaches approximately $10^{15}$ ions $/ \mathrm{cm}^{2}$. The $\mathrm{O}_{2}$ concentration decreases with the depth of irradiated glass at the ion fluence of $2 \times 10^{16}$ ions $/ \mathrm{cm}^{2}$. A sodium depleted layer at the surface and a depleted zone at around the penetration depth of $5 \mathrm{MeV} \mathrm{Xe}$ ions are observed. The thickness of the sodium depleted layer increases with the irradiation fluence. Moreover, comparing with previous results after electron and $\mathrm{Ar}$ ion irradiation, it can be concluded that the nuclear energy deposition can partially inhibit the formation of molecular oxygen and increase the threshold value of electron energy deposition for the molecular oxygen formation.

Keywords: borosilicate glass, ion irradiation, molecular oxygen, sodium migration

\footnotetext{
* Corresponding author.

E-mail address: chenl@1zu.edu.cn (L. Chen).
} 


\section{Introduction}

Borosilicate glass is wildly used in the industries related with radiation, such as neutron guide substrate, nonpolar lamp-envelops and immobilization of high-level nuclear wastes (HLW) [1-3]. Irradiation-induced damages may change both the physical and chemical properties of borosilicate glass. Understanding irradiation effects in microstructural evolution of borosilicate glass is critical to predict its performance after long-term interactions with the irradiation environment.

The irradiation effects in the microstructures of borosilicate glasses have been extensively studied. With external electron irradiation, an increase of the glass polymerization, a decrease in the average $\mathrm{Si}-\mathrm{O}-\mathrm{Si}$ bond angle, the transformation of $\left[\mathrm{BO}_{4}\right]$ to $\left[\mathrm{BO}_{3}\right]$, several paramagnetic defects, the formation of oxygen molecules/bubbles and the phase separation have been observed [4-10]. The electron irradiation effects have been mainly correlated to the migration and aggregation of sodium ions during irradiation. After ion irradiation, some evolutions of microstructure were also observed in the borosilicate glasses, such as a decrease in the network polymerization, a decrease in the average $\mathrm{Si}-\mathrm{O}-\mathrm{Si}$ bond angle, a decrease in the mean ring size and the transformation of $\left[\mathrm{BO}_{4}\right]$ to $\left[\mathrm{BO}_{3}\right]$, etc [11-14]. The formation of molecular oxygen has also been evidenced by the Raman spectroscopy in the ion irradiated borosilicate glasses $[14,15]$. Migration and aggregation of sodium have also been invoked to explain the formation of molecular oxygen in $2 \mathrm{MeV}$ Ar-ions irradiated borosilicate glasses [14]. The alkali migration in the silicate glasses induced by $\mathrm{keV}$ heavy ion irradiation has been widely observed $[16,17]$. The alkali depletion on the surface has been explained by a preferential sputtering mechanism of alkali atoms and an enhanced diffusion over the range of 
implanted ions. However, to our knowledge, we did not find in the literature studies analyzing alkali migration in $\mathrm{MeV}$ ion irradiated glass, which is important to understand the microstructural evolution induced by $\mathrm{MeV}$ ion irradiation. Since the alkali sputtering cross-section is closely correlated to the stopping power regimes of incident ions, more experiments should be performed.

Moreover, when the borosilicate glass is subjected to simultaneous irradiation with different particles, such as electrons, gamma rays, and ions, the radiation effects can be significantly affected by the existing of multi-particle irradiation scenarios. Simultaneous irradiation with multiple particles and sequential particle irradiations have provided some insights in the mechanisms of the damage formation and subsequent damage evolution [18]. Comparison studies with the radiation effects induced by different particles can also provide information on the mechanisms associated with radiation effects induced by the multi-particle irradiation scenarios.

In this paper, a commercial sodium borosilicate glass was investigated through external irradiation of $5 \mathrm{MeV}$ Xe ions. The evolution of glass network structure with Xe ion fluence was characterized by Raman spectroscopy. ToF-SIMS depth profiles were acquired to get the information on the changes in sodium contents along the depth of irradiated glasses. A comparison studies with previous results after electron and Ar ion irradiation were performed to discuss the evolution of molecular oxygen, in particularly considering the effects of electronic and nuclear process, respectively.

\section{Experimental}

\subsection{Chemical compositions}


The chemical composition of a commercial borosilicate glass used in the experiment is presented in Table 1. The glass sample was supplied by the Quartz and Special Glasses Institute of China Building Materials Academy. The sample with a size of $10 \times 10 \times 1 \mathrm{~mm}^{3}$, was fine polished and ultrasonically cleaned prior to ion irradiation.

\subsection{Irradiation conditions}

Irradiation with $5 \mathrm{MeV} \mathrm{Xe}^{23+}$ ions was conducted by a $320 \mathrm{kV}$ electron cyclotron resonance (ECR) ion source in the national laboratory of the Heavy Ion Accelerator Research Facility, Lanzhou (HIRFL). The beam current was approximately $4.2 \mu \mathrm{A}$, and the current density was approximately $2.1 \mu \mathrm{A} \mathrm{cm}{ }^{-2}$. Different fluences as $10^{13}-2.0 \times 10^{16} \mathrm{Xe}$ ions $/ \mathrm{cm}^{2}$ were used in our irradiation experiments.

The stopping power (electronic process and collision events) versus the projectile ranges in $5 \mathrm{MeV}$ Xe ion irradiated glass calculated by the SRIM2008 code are shown in Fig. 1. It is obviously that the electronic process dominates in the front of particle track and the nuclear process focuses around the projectile range. The penetration range of Xe ions in this glass is approximately $1.76 \mu \mathrm{m}$. The nuclear and electronic energy depositions in Xe ion irradiated glass versus the irradiation fluence are shown in Table 2 . This table shows that the nuclear energy deposition in the glass is more than five times of the electronic energy deposition for each fluence.

\subsection{Characterization methods}

The Raman spectra were obtained using a LabRAM HR 800 micro-spectrometer using the $532 \mathrm{~nm}$ line of an argon ion laser with an output power of $100 \mathrm{~mW}$; the experiments were performed with $\times 100$ objective in confocal mode. The spectrometer resolution is less than 1 
$\mathrm{cm}^{-1}$. Under the present experimental conditions, the optical penetration depth of Raman excitation light was approximately $1 \mu \mathrm{m}$ [12]. In order to perform the Raman depth profile experiments, the irradiated glass at the fluence of $2.0 \times 10^{16}$ ions $/ \mathrm{cm}^{2}$ was cut and glued parallel to the glass of the $\mathrm{L}$ bracket of a tripod polisher. The irradiated surface was polished at an angle of approximately $5^{\circ}$ with respect to the glass surface of the L bracket. After mechanical polishing, the Raman spectra were acquired at different spots on the polished surface, which corresponding to different depth of the irradiated glass.

A ToF-SIMS spectrometer (TOF.SIMS ${ }^{5}$, IONTOF GmbH, Münster, Germany) was used to perform the depth profiling experiments. A $20 \mathrm{keV} \mathrm{Ar}_{\mathrm{n}}{ }^{+}$beam was used as a sputtering

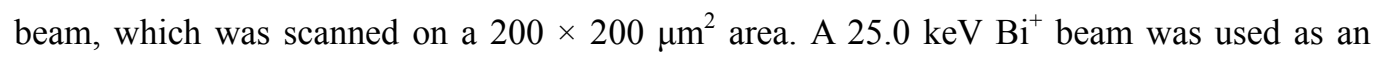
analyzing beam, which was scanned on a $50 \times 50 \mu \mathrm{m}^{2}$ area at the center of the sputtering crater. More experimental details can be seen in our previous publication [20]. After the SIMS measurement, a stylus profilometer was used to measure the crater depth, and a constant sputtering rate was assumed. All the depth profiles show the Poisson corrected intensity expressed in counts.

\section{Results and Discussion}

\subsection{Raman spectra of pristine and irradiated glasses}

The Raman spectra of the pristine and irradiated glasses for Raman shifts between 200 and $1800 \mathrm{~cm}^{-1}$ are presented in Fig. 2. The raw Raman spectra were normalized to the intensity of broad band observed around $490 \mathrm{~cm}^{-1}$ and shifted vertically for clarity. The Raman spectrum of this glass was described in detail elsewhere [14]. As shown in Fig. 2, there are approximately no differences in these peaks located at approximately 630 and 800 
$\mathrm{cm}^{-1}$ between the Raman spectra of pristine and irradiated glasses. However, it can be found that the peak position of the $\mathrm{Si}-\mathrm{O}-\mathrm{Si}$ vibration band at $490 \mathrm{~cm}^{-1}$ is slightly shifted toward higher Raman shifts after irradiation as shown in the inset of Fig. 2. Since there is generally an inverse correlation between the frequency of this band and the $\mathrm{Si}-\mathrm{O}-\mathrm{Si}$ angle in condensed silicate [21], which indicates that a decrease in the average $\mathrm{Si}-\mathrm{O}-\mathrm{Si}$ angle with the irradiation fluence. Moreover, a new weak peak at $602 \mathrm{~cm}^{-1}$ is observed in the Raman spectra of the irradiated glasses, and its intensity is gradually increased with the irradiation fluence. Since the weak shoulder at around $602 \mathrm{~cm}^{-1}$ has been assigned to the $\mathrm{D}_{2}$ "defect" peak involving the three-membered rings of $\mathrm{SiO}_{4}$ tetrahedra $[22,23]$, the results suggest that an increase in the population of three-membered rings with the irradiation fluence. The results of a decrease in the average $\mathrm{Si}-\mathrm{O}-\mathrm{Si}$ angle and an increase in the population of three-membered rings are consistent with previous molecular dynamics studies on French nuclear glasses [24, 25], suggesting that these variations are primary due to a decrease in the mean boron coordination number and an increase in the degree of disorder.

There are also some differences in the relative percentages for the $\mathrm{Q}^{\mathrm{n}}$ species in the pristine glass compared with the irradiated glasses at high ion fluence. The intensity of the band at $960 \mathrm{~cm}^{-1}$ corresponding to $\mathrm{Q}^{2}$ species increases relatively to the band of $\mathrm{Q}^{3}$ species at $1080 \mathrm{~cm}^{-1}$, which indicates that some modifications in polymerization of the silicate network occurred after Xe ions irradiation.

Moreover, as shown in Fig. 2 and Fig. 3, a weak and narrow peak appears at about 1550 $\mathrm{cm}^{-1}$ on the Raman spectrum of irradiated glass surface. This peak corresponds to the stretching vibration mode of the $\mathrm{O}-\mathrm{O}$ bond in molecular oxygen $\mathrm{O}_{2}$. The intensity of the $\mathrm{O}_{2}$ 
peak increases with the irradiation fluence, which can be attributed to the formation of molecular oxygen induced by Xe ion irradiation $[4,7]$.

\subsection{Raman depth profiles of Xe irradiated glass at $2.0 \times 10^{16}$ ions $/ \mathrm{cm}^{2}$}

In order to analysis the modifications of the glass network structure in the depth induced by Xe ion irradiation, the Raman depth profile experiments were performed. The raw Raman depth profile results of Xe ion irradiated glass at $2.0 \times 10^{16}$ ions $/ \mathrm{cm}^{2}$ are shown in Fig. 4. The $\mathrm{D}_{2}$ band, the modifications in polymerization of the silicate network and the $\mathrm{O}_{2}$ peak can be observed in the Raman spectra acquired at the surface and the depth of 0.5 and $1 \mu \mathrm{m}$, which is consistent with the penetration depth of $5 \mathrm{MeV}$ Xe ions. In addition, the intensity of the $\mathrm{O}_{2}$ peak decreases with the depth as shown in the inset of Fig. 4.

\subsection{ToF-SIMS depth profiles}

ToF-SIMS depth profiles of the pristine and irradiated glasses were also acquired to get the information on the compositional changes in depth. Fig. 5 depicts the ToF-SIMS depth profiles acquired on the pristine and irradiated glass at $9 \times 10^{15}$ ions $/ \mathrm{cm}^{2}$. All signals with the depth are normalized to ${ }^{28} \mathrm{Si}^{+}$. The depth distributions of $\mathrm{B}$ and $\mathrm{O}$ in the irradiated glass at $9 \times 10^{15}$ ions $/ \mathrm{cm}^{2}$ have approximately no differences in the irradiated region in comparison to the pristine sample. However, the depth distribution of $\mathrm{Na}$ is significantly changed after irradiation. For the Na profile of irradiated glass at $9 \times 10^{15}$ ions $/ \mathrm{cm}^{2}$, one can note a near surface layer depleted in $\mathrm{Na}$, bounded by a slightly rise of the $\mathrm{Na}$ concentration, higher than the measured for the pristine sample, followed a depleted zone in the depth around the penetration depth of $5 \mathrm{MeV} \mathrm{Xe}$ ions. 
The evolutions of Na signals as a function of the Xe ion fluences are presented in Fig. 6. The Xe distribution is also displayed to compare the depth profile of $\mathrm{Na}$ signal with the penetration depth of $5 \mathrm{MeV}$ Xe ions, which is determined using SRIM 2008 full-cascade simulations. As shown in Fig. 6, the sodium depleted layer appears at the top surface $(<150$ $\mathrm{nm}$ ) at low ion fluence (eg. $10^{14}$ ions $/ \mathrm{cm}^{2}$ ). The thickness of the depleted layer at the top surface increases with the irradiation fluence. The depleted zone in the depth around the penetration depth of $5 \mathrm{MeV} \mathrm{Xe}$ ions starts to show in the irradiated glass at $10^{15}$ ions $/ \mathrm{cm}^{2}$, and the size of the depleted zone appears to extend toward both sides with the irradiation fluence. At the highest fluence $\left(2 \times 10^{16} \mathrm{ions} / \mathrm{cm}^{2}\right)$, the entire near surface region over the penetration range of $5 \mathrm{MeV} \mathrm{Xe}$ ions is depleted.

\section{Discussion}

The formation of molecular oxygen has been observed in electron and $\mathrm{Kr}$ ion irradiated borosilicate glasses $[4,7,15]$. Previous results on this borosilicate glass have also shown the formation of molecular oxygen after electron and $\operatorname{Ar}$ ion irradiation $[9,14]$. The increasing concentration of molecular oxygen dissolved in the irradiated glasses may lead to the formation of oxygen bubbles, which can decrease the brittleness of the glass and enhance its

crack propagation resistance. Migration and aggregation of sodium have been invoked to explain the formation of molecular oxygen. In addition, the tetrahedral to trigonal boron conversion has also been considered as one of the mechanisms which lead to the molecular oxygen formation [26]. The transformation of B (IV) to B (III) in the borosilicate glasses has been confirmed by both the ion irradiation experiments and molecular dynamics simulation $[12,24,25]$. The migration of sodium to the surface is evidenced by the ToF-SIMS depth 
profile results as shown in Fig. 6. The depleted layer at the surface is consistent with previous studies on heavy ion irradiated silicate glasses, which has been explained by a preferential sputtering mechanism of alkali atoms and an enhanced diffusion over the range of implanted ions $[16,17]$.

Battaglin et al. have studied the dependence of alkali sputtering cross-section on the stopping power of incident ions, suggesting that the electronic excitations play the dominant role in the alkali sputtering process [17]. Previous studies on electron irradiated borosilicate glasses also suggested that electron energy deposition dominates the process involved the formation of molecular oxygen [4, 7]. As shown in Fig. 7, the intensity of the $\mathrm{O}_{2}$ peak increases with the electron energy deposition after electron, Ar and Xe irradiation. However, the threshold value $(\mathrm{T})$ of electron energy deposition for the molecular oxygen formation depends on the nature of the incident particles: $\mathrm{T}$ (electron) $<\mathrm{T}(\mathrm{Ar})<\mathrm{T}(\mathrm{Xe})$. The dependence can be attributed to the relative proportion of electronic processes and atomic collisions, which depends on the mass and the energy of particles. The electron deposits most of the energy as ionizing radiation rather than as nuclear stopping. The nuclear energy deposition in the case of $\mathrm{Ar}$ ion irradiation is slightly more than the energy deposition of electrons as shown in the table 2 in Ref. [14]. In the case of Xe ion irradiation, the nuclear energy deposition is more than five times of the electronic energy deposition as shown in table 2. Therefore, it can be concluded that the nuclear energy deposition can partially inhibit the formation of molecular oxygen and increase the threshold value of electron energy deposition for the molecular oxygen formation.

The distribution of molecular oxygen with the depth of electron irradiated borosilicate 
glasses has been studied [7, 9], suggesting that molecular oxygen migrates to the glass surface through percolation paths as alkalis $[27,28]$. The migration of sodium to the surface and preferential sputtering of sodium to vacuum induced by Xe ion irradiation are verified by the ToF-SIMS depth profile results as shown in Fig. 6. According to the mechanism for bubble formation based on short range oxygen diffusion from the migration of the modifier alkaline ions creating local super saturation of oxygen which precipitates out as bubbles [29], the molecular oxygen can be easily formed near free surfaces where $\mathrm{Na}^{+}$cation can escape. The decrease in the $\mathrm{O}_{2}$ concentration with the depth of irradiated glass at $2 \times 10^{16}$ ions $/ \mathrm{cm}^{2}$ as shown in the inset of Fig. 4 is consistent with this mechanism. Therefore, in our study no clear evidence allows to assert the migration of molecular oxygen to the surface during Xe ion irradiation. However, it also should be noted that there are nearly approximately no differences in the oxygen concentration at different depths and different irradiation fluences as observed in ToF-SIMS depth profiles. This can be understood since the Raman technique is much more sensitive, the differences in the oxygen concentration were may be too small to be detected by ToF-SIMS.

The decrease in the mean $\mathrm{Si}-\mathrm{O}-\mathrm{Si}$ angle has been evidenced by both the ion/electron irradiation experiments and molecular dynamics simulations on the borosilicate glasses $[4$, $11-14,24,25]$, which is generally correlated with a decrease of the average rings size in the glass structure. This result is supported in this work by the increase of the $\mathrm{D}_{2}$ band intensity correlated with an increase of three-membered siloxane rings during ion irradiation. Both the decreases in the mean $\mathrm{Si}-\mathrm{O}-\mathrm{Si}$ angle and the mean ring size have been correlated with the increase of density in silica and borosilicate glasses [4, 13, 23]. However, recent results 
suggested that these modifications induced by the accumulation of ballistic damage cannot be associated to the density evolution because they appear both in pure silica, that shows a densification, and in the borosilicate glass, that swells [24].

The relative increase of the $\mathrm{Q}^{2} / \mathrm{Q}^{3}$ species concentration ratio at high ion fluence is confirmed in the Raman spectra as shown in Fig. 2. However, Raman measurements are weakly sensitive to the $\mathrm{Q}^{4}$ species, which represents the majority of the $\mathrm{Q}^{\mathrm{n}}$ species in the glass network. Therefore, it is difficult to conclude about the polymerization changes only based on the Raman results. In general for borosilicate glass, the polymerization of glass network is closely associated with the alkali concentration if we don't consider the specific role of alkali as a charge compensator of boron in tetrahedral environment. The increases in polymerization of the borosilicate glass after $2.1 \mathrm{MeV} \mathrm{Kr}$ and $1 \mathrm{MeV}$ He irradiation were also correlated to the depletion of sodium near the surface with preferential sputtering of sodium [15]. In this work, the depletion of sodium near the surface induced by $\mathrm{MeV}$ ion irradiation is confirmed by ToF-SIMS depth profiles. The thickness of the depleted layer at the surface of irradiated glass at $2 \times 10^{16}$ ions $/ \mathrm{cm}^{2}$ exceeds the optical penetration depth of Raman excitation light under the present experimental conditions, suggesting that an increase of glass polymerization induced by Xe ion irradiation at high ion fluence.

\section{Conclusion}

The evolutions of molecular oxygen formation and sodium migration in $5 \mathrm{MeV} \mathrm{Xe}$ ion irradiated borosilicate glass have been studied. A sodium depleted layer at the surface and a depleted zone at around the penetration depth of $5 \mathrm{MeV} \mathrm{Xe}$ ions are observed. The formation of molecular oxygen and an increase of glass polymerization are also evidenced in the 
irradiated glasses at high ion fluence, which are correlated to the migration and preferential sputtering of sodium induced by $\mathrm{MeV}$ ion irradiation. The nuclear energy deposition can partially inhibit the formation of molecular oxygen and increase the threshold value of electron energy deposition for the molecular oxygen formation.

\section{Acknowledgements}

This work is supported by the National Nature Science Foundation of China (NSFC, No. 11505084). The ECR-group and Public Center for Characterization and Test in Institute of Modern Physics, Lanzhou, is acknowledged for providing technical supports. ToF-SIMS measurement was performed under a general user proposal of EMSL, a national scientific user facility sponsored by DOE Office of Biological and Environmental Research and located at PNNL.

\section{References}

[1] R. Boffy, M. Kreuz, J. Beaucour, U. Köster, F.J. Bermejo, Why neutron guides may end up breaking down? Some results on the macroscopic behaviour of alkaliborosilicate glass support plates under neutron irradiation, Nucl. Instr. Meth. B 358 (2015) 179-187.

[2] Qingyan Wang, Hongbin Geng, Shiyu He, Dezhuang Yang, Zhonghua Zhang, Xiubo Qin, Zhuoxin Li, Effects of $80 \mathrm{KeV}$ proton radiation on the optical properties and microstructure of type-GG17 glass as rubidium lamp envelope, Nucl. Instr. Meth. B 267 (2009) 2489-2494.

[3] W.J. Weber, R.C. Ewing, C.A. Angell, G.W. Arnold, A.N. Cormack, J.M. Delaye, D.L. 
Gscom, L.W. Hobbs, A. Navrotsky, D.L. Price, A.M. Stoneham, M.C. Weinberg, Radiation effects in glasses used for immobilization of high-level waste and plutonium disposition, J. Mater. Res. 12 (8) (1997) 1946-1978.

[4] B. Boizot, G. Petite, D. Ghaleb, B. Reynard, G. Calas, Raman study $\beta$-irradiated glasses, J. Non-Cryst. Solids 243 (1999) 268-272.

[5] Bruno Boizot, Guillaume Petite, Dominique Ghaleb, Nadia Pellerin, Franck Fayon, Bruno Reynard, Georges Calas, Migration and segregation of sodium under $\beta$-irradiation in nuclear glasses, Nucl. Instr. Meth. B 166-167 (2000) 500-504.

[6] B. Boizot, G. Petite, D. Ghaleb, G. Calas, Dose, dose rate and irradiation temperature effects in $\beta$-irradiated simplified nuclear waste glasses by EPR spectroscopy, J. Non-Cryst. Solids 283 (2001) 179-185.

[7] N. Ollier, B. Boizot, B. Reynard, D. Ghaleb, G. Petite, Analysis of molecular oxygen formation in irradiated glasses: a Raman depth profile study, J. Nucl. Mater. 340 (2005) 209-213.

[8] K. Sun, L.M. Wang, R.C. Ewing, W.J. Weber, Effects of electron irradiation in nuclear waste glasses, Phil. Mag. 85 (2005) 597-608.

[9] Chen Liang, Wang Tie-Shan, Zhang Gen-Fa, Yang Kun-Jie, Peng Hai-Bo, Zhang Li-Min, XPS and Raman studies of electron irradiated sodium silicate glass, Chin. Phys. B 22 (2013) 126101.

[10] L. Chen, W. Yuan, S. Nan, X. Du, D.F. Zhang, P. Lv, H.B. Peng, T.S. Wang, Study of modifications in the mechanical properties of sodium aluminoborosilicate glass induced by heavy ions and electrons, Nucl. Instr. Meth. B 370 (2016) 42-48. 
[11] S. Peuget, J.-M. Delaye, C. Jégou, Specific outcomes of the research on the radiation stability of the French nuclear glass towards alpha decay accumulation, J. Nucl. Mater. 444 (2014) 76-91.

[12] J. de Bonfils, S. Peuget, G. Panczer, D. de Ligny, S. Henry, P.-Y. Noël, A. Chenet, B. Champagnon, Effect of chemical composition on borosilicate glass behavior under irradiation, J. Non-Cryst. Solids 356 (2010) 388-393.

[13] L. Chen, T.S. Wang, K.J. Yang, H.B. Peng, G.F. Zhang, L.M. Zhang, H. Jiang, Q. Wang, Raman study of $\mathrm{Kr}$ ion irradiated sodium aluminoborosilicate glass, Nucl. Instr. Meth. B 307 (2013) 566-569.

[14] G.F. Zhang, T.S. Wang, K.J. Yang, L. Chen, L.M. Zhang, H.B. Peng, W. Yuan, F. Tian, Raman spectra and nano-indentation of Ar-irradiated borosilicate glass, Nucl. Instr. Meth. B 316 (2013) 218-221.

[15] A. Abbas, Y. Serruys, D. Ghaleb, J.M. Delaye, B. Boizot, B. Reynard, G. Calas, Evolution of nuclear glass structure under a-irradiation, Nucl. Instr. Meth. B 166-167 (2000) 445-450.

[16] G. Battaglin, G.Della Mea, G. De Marchi, P. Mazzoldi, A. Miotello, Alkali migration in ion irradiated glasses, Nucl. Instr. Meth. B 1 (1984) 511-515.

[17] G. Battaglin, A. Boscoletto, G. Della Mea, G. De Marchi, P. Mazzoldi, A. Miotello, B. Tiveron, Heavy ion irradiation of glasses: Enhanced diffusion and preferential sputtering of alkali elements, Radiat. Eff. 98 (1986) 101-108.

[18] A.H. Mir, I. Monnet, M. Toulemonde, S. Bouffard, C. Jegou, S. Peuget, Mono and sequential ion irradiation induced damage formation and damage recovery in oxide 
glasses: stopping power dependence of the mechanical properties, J. Nucl. Mater. 469 (2016) 244-250.

[19] J.F. Ziegler, J.P. Biersack, U. Littmark (Eds.), The Stopping Range of Ions in Matter, vols. 2-6, Pergamon Press, New York, 1985.

[20] Zhaoying Wang, Bingwen Liu, Evan W. Zhao, Ke Jin, Yingge Du, James J. Neeway, Joseph V. Ryan, Dehong Hu, Kelvin H. L. Zhang, Mina Hong, Solenne Le Guernic, Suntharampilai Thevuthasan, Fuyi Wang, Zihua Zhu, Argon cluster sputtering source for ToF-SIMS depth profiling of insulating materials: high sputter rate and accurate interfacial information, J. Am. Soc. Mass Spectrom. 26 (2015) 1283-1290.

[21] P. Mcmillan, Structural studies of silicate glasses and melts-applications and limitations of Raman spectroscopy, Amer. Miner. 69 (1984) 622-644.

[22] F.L. Galeener, R.A. Barrio, E. Martinez, R.J. Elliott, Vibrational Decoupling of Rings in Amorphous Solids, Phys. Rev. Lett. 53 (1984) 2429-2432.

[23] B. Boizot, S. Agnello, B. Reynard, R. Boscaino, G. Petite, Raman spectroscopy study of $\beta$-irradiated silica glass, J. Non-Cryst. Solids 325 (2003) 22-28.

[24] J.-M. Delaye, S. Peuget, G. Bureau, G. Calas, Molecular dynamics simulation of radiation damage in glasses, J. Non-Cryst. Solids 357 (2011) 2763-2768.

[25] J.-M. Delaye, S. Peuget, G. Calas, L. Galoisy, Comparative effects of thermal quenching and ballistic collisions in $\mathrm{SiO}_{2}-\mathrm{B}_{2} \mathrm{O}_{3}-\mathrm{Na}_{2} \mathrm{O}$ glass, Nucl. Instr. Meth. B 326 (2014) 256259.

[26] N. Ollier, T. Charpentier, B. Boizot, G. Petite, A structural approach by MAS NMR spectroscopy of mechanisms occurring under $\beta$-irradiation in mixed alkali 
aluminoborosilicate glasses, J. Phys.: Condens. Matter 16 (2004) 7625-7635.

[27] K. Jurek, O. Gedeon, V. Hulinsky, Potassium Migration in Silica Glass During Electron Beam Irradiation, Mikrochim. Acta 15 (Suppl.) (1998) 269-272.

[28] Karel Jureka, Ondrej Gedeon, Analysis of alkali-silicate glasses by electron probe analysis, Spectrochimica Acta Part B 58 (2003) 741-744.

[29] J.F. Denatale, D.G. Howitt, A mechanism for radiation danage in silicate glasses, Nucl. Instr. Meth. B 1(1984) 489-497. 


\section{Figure/Table Captions}

Table 1. Chemical composition (wt.\%) of the borosilicate glass.

Fig.1. Stopping power in the glass versus depth for $5 \mathrm{MeV}$ Xe ions irradiation (SRIM 2008

calculation [19]).

Table 2. Nuclear and electronic energy deposited in Xe ion irradiated glass versus the irradiation fluence.

Fig.2. Raman spectra of Xe ion irradiated glasses.

Fig.3. Raman spectra in the $1400 \mathrm{~cm}^{-1} \sim 1700 \mathrm{~cm}^{-1}$ range of the pristine and Xe ion irradiated glasses.

Fig.4. Raman depth profile results of Xe ion irradiated glass at $2.0 \times 10^{16}$ ions $/ \mathrm{cm}^{2}$.

Fig.5. ToF-SIMS depth profiles of the pristine glass and irradiated glass at $9 \times 10^{15}$ ions $/ \mathrm{cm}^{2}$.

Fig.6. Evolution of ToF-SIMS depth profiles of Na signals versus Xe ion fluence (ions $/ \mathrm{cm}^{2}$ ).

Fig.7. Evolutions of $\mathrm{O}_{2}$ peak intensity versus electron energy deposition. (The dashed lines are guides for the eyes.) 
Table 1

\begin{tabular}{cccccccc}
\hline Composition & $\mathrm{SiO}_{2}$ & $\mathrm{Na}_{2} \mathrm{O}$ & $\mathrm{Al}_{2} \mathrm{O}_{3}$ & $\mathrm{~B}_{2} \mathrm{O}_{3}$ & $\mathrm{CeO}_{2}$ & $\mathrm{ZnO}+\mathrm{MgO}$ & $\mathrm{SrO}$ \\
\hline wt.\% & $70 \pm 5$ & $17 \pm 3$ & $5 \pm 1$ & $4 \pm 1$ & $4 \pm 1$ & $1 \pm 0.5$ & $1 \pm 0.5$ \\
\hline
\end{tabular}

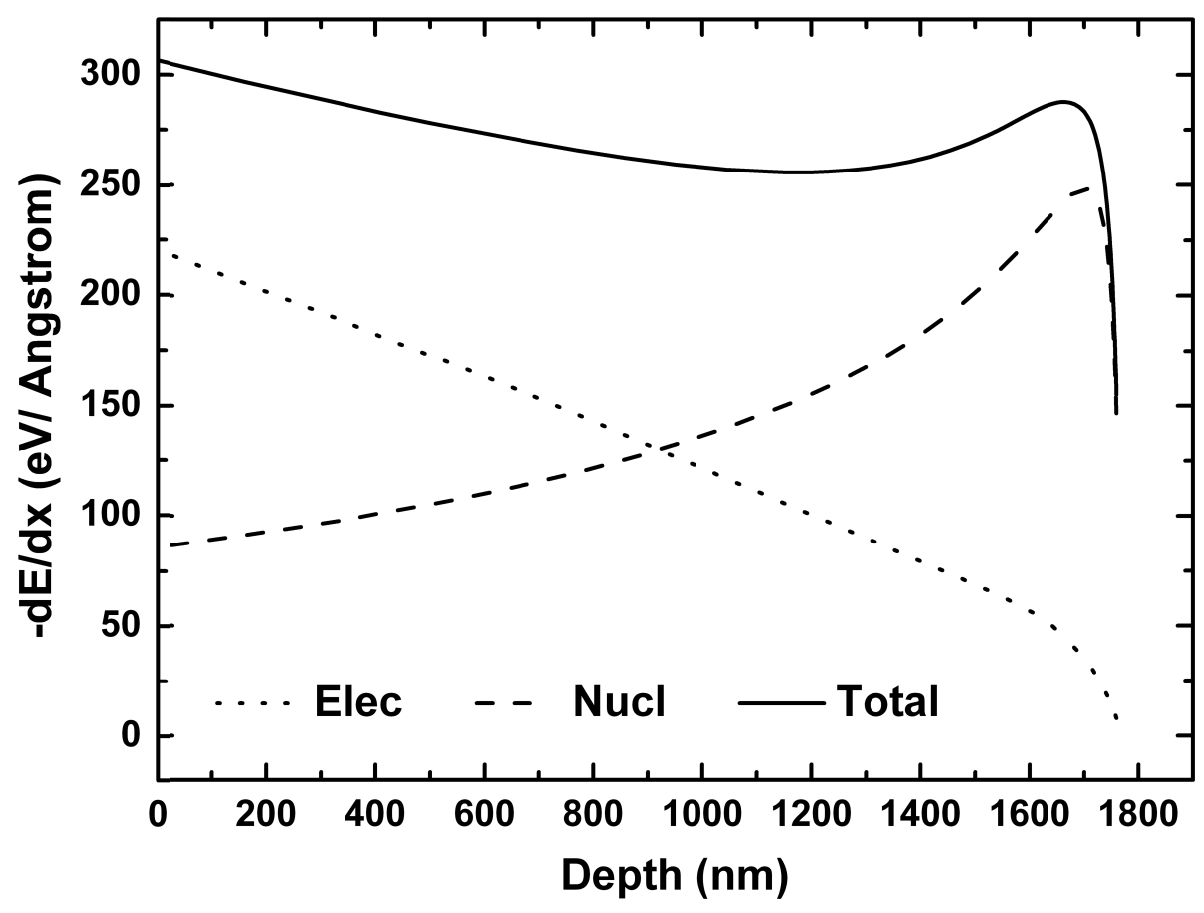

Fig. 1 
Table 2

\begin{tabular}{ccc}
\hline Fluence $\left(\right.$ ions $\left./ \mathrm{cm}^{2}\right)$ & $\mathrm{E}_{\text {nucl }}\left(\mathrm{keV} / \mathrm{cm}^{3}\right)$ & $\mathrm{E}_{\text {elec }}\left(\mathrm{keV} / \mathrm{cm}^{3}\right)$ \\
\hline $1.0 \times 10^{13}$ & $6.26 \times 10^{20}$ & $1.13 \times 10^{20}$ \\
$1.0 \times 10^{14}$ & $6.26 \times 10^{21}$ & $1.13 \times 10^{21}$ \\
$5.0 \times 10^{14}$ & $3.13 \times 10^{22}$ & $5.65 \times 10^{21}$ \\
$1.0 \times 10^{15}$ & $6.26 \times 10^{22}$ & $1.13 \times 10^{22}$ \\
$4.0 \times 10^{15}$ & $2.51 \times 10^{23}$ & $4.52 \times 10^{22}$ \\
$9.0 \times 10^{15}$ & $5.63 \times 10^{23}$ & $1.02 \times 10^{23}$ \\
$1.4 \times 10^{16}$ & $8.76 \times 10^{23}$ & $1.58 \times 10^{23}$ \\
$2.0 \times 10^{16}$ & $1.25 \times 10^{24}$ & $2.26 \times 10^{23}$ \\
\hline
\end{tabular}




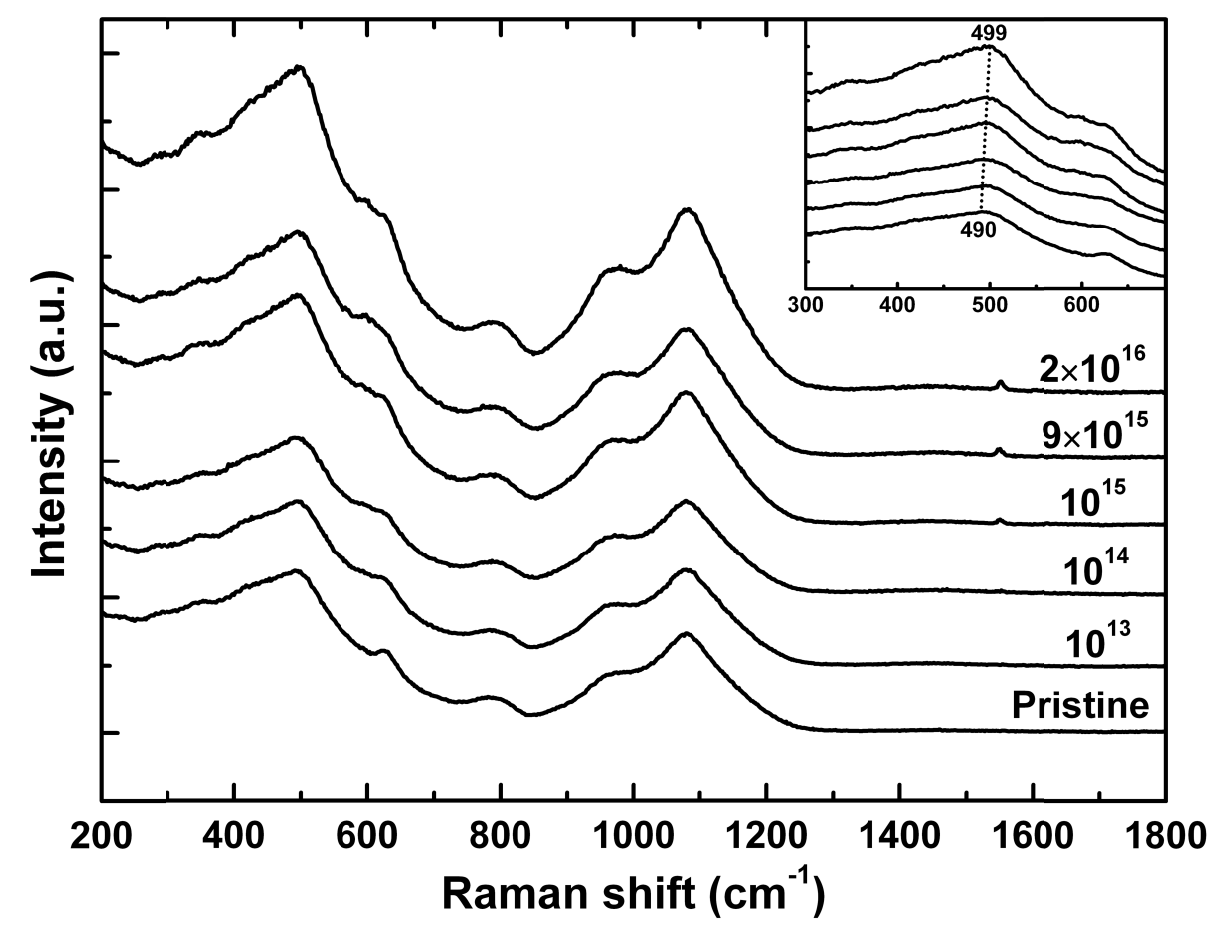

Fig. 2 


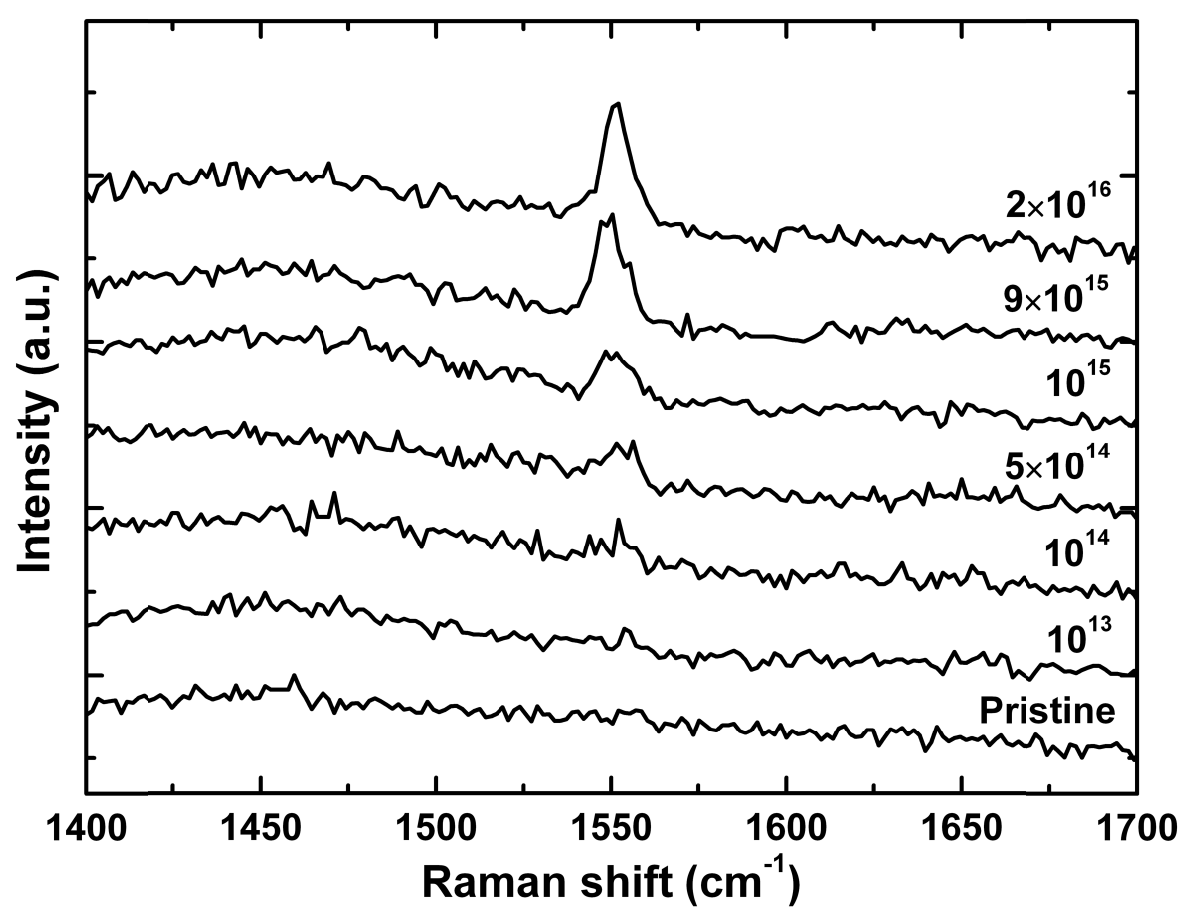

Fig. 3 


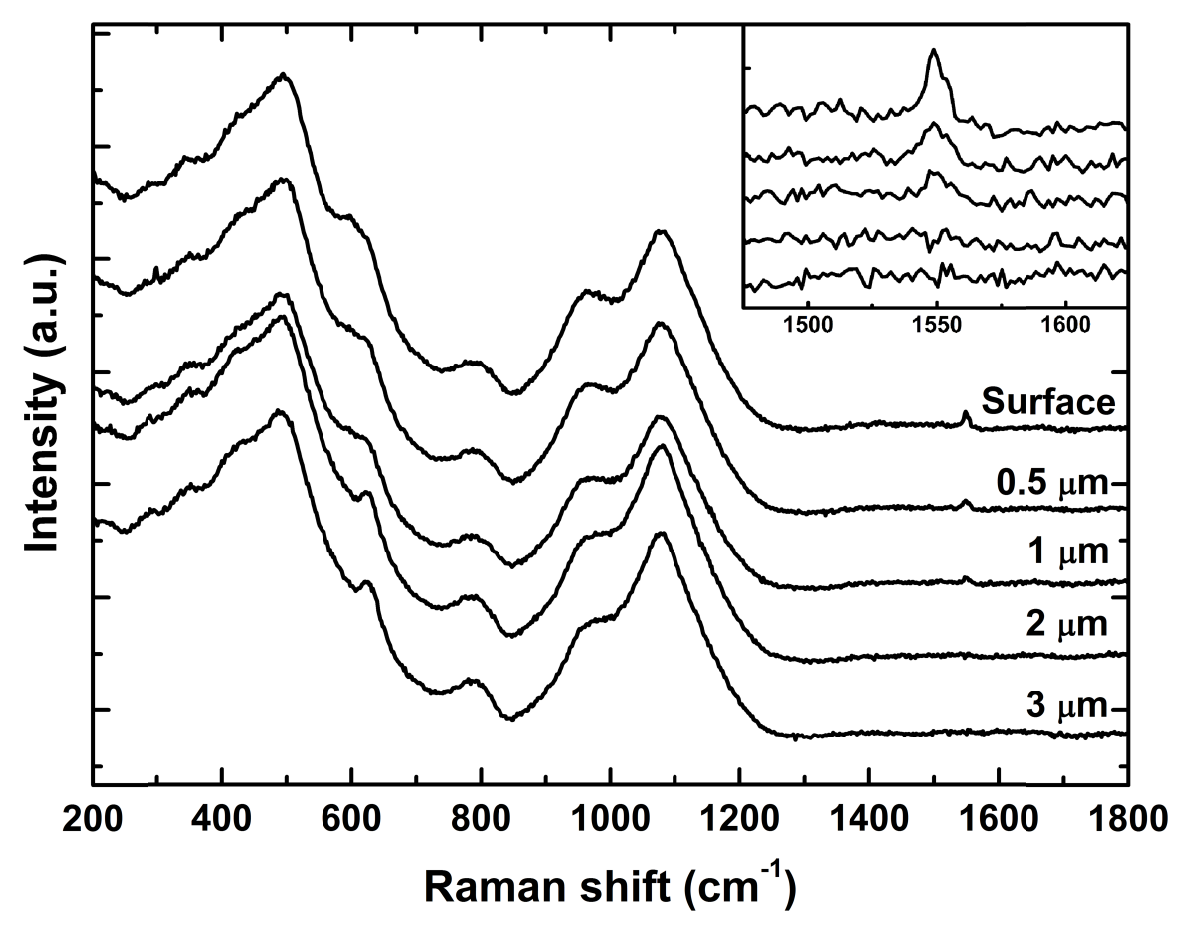

Fig. 4 


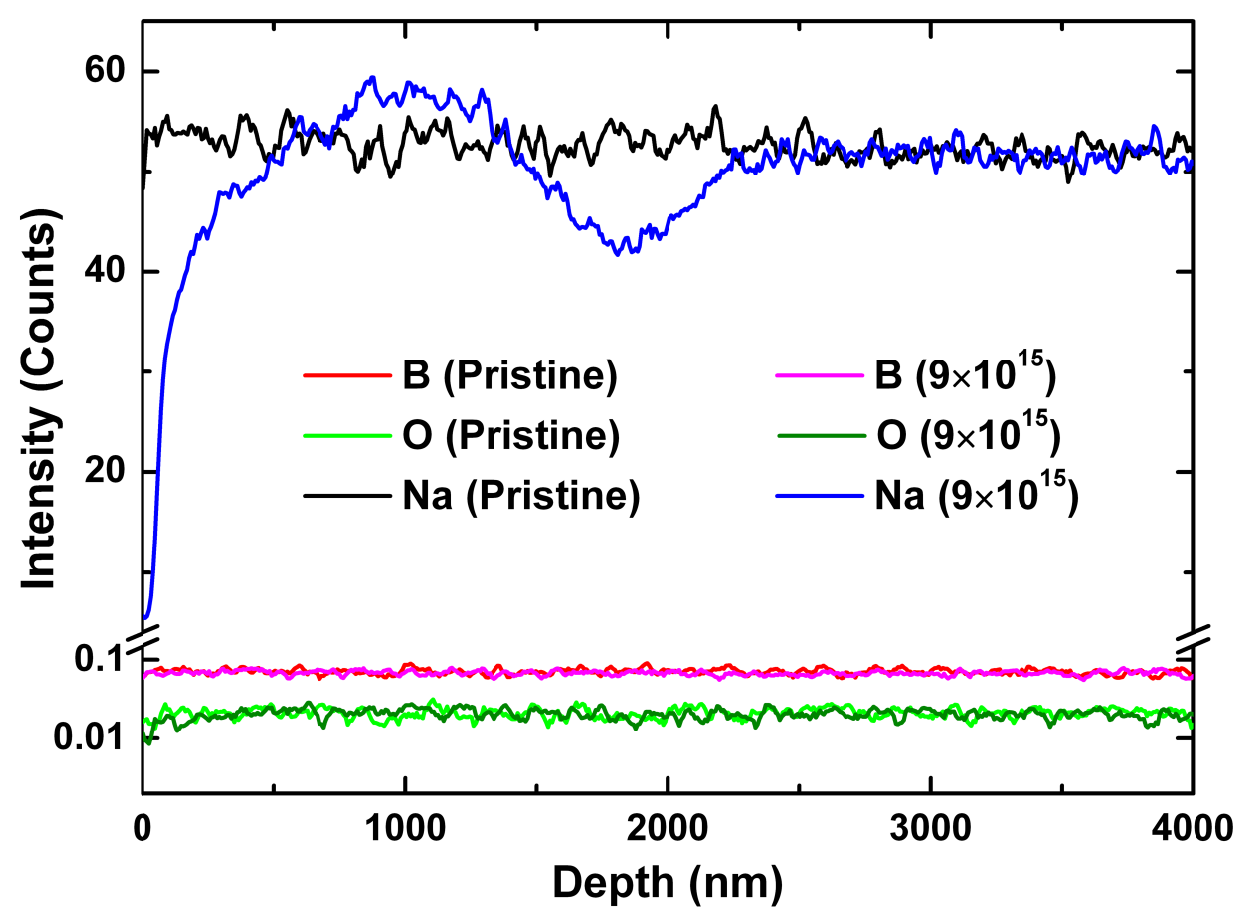

Fig. 5 


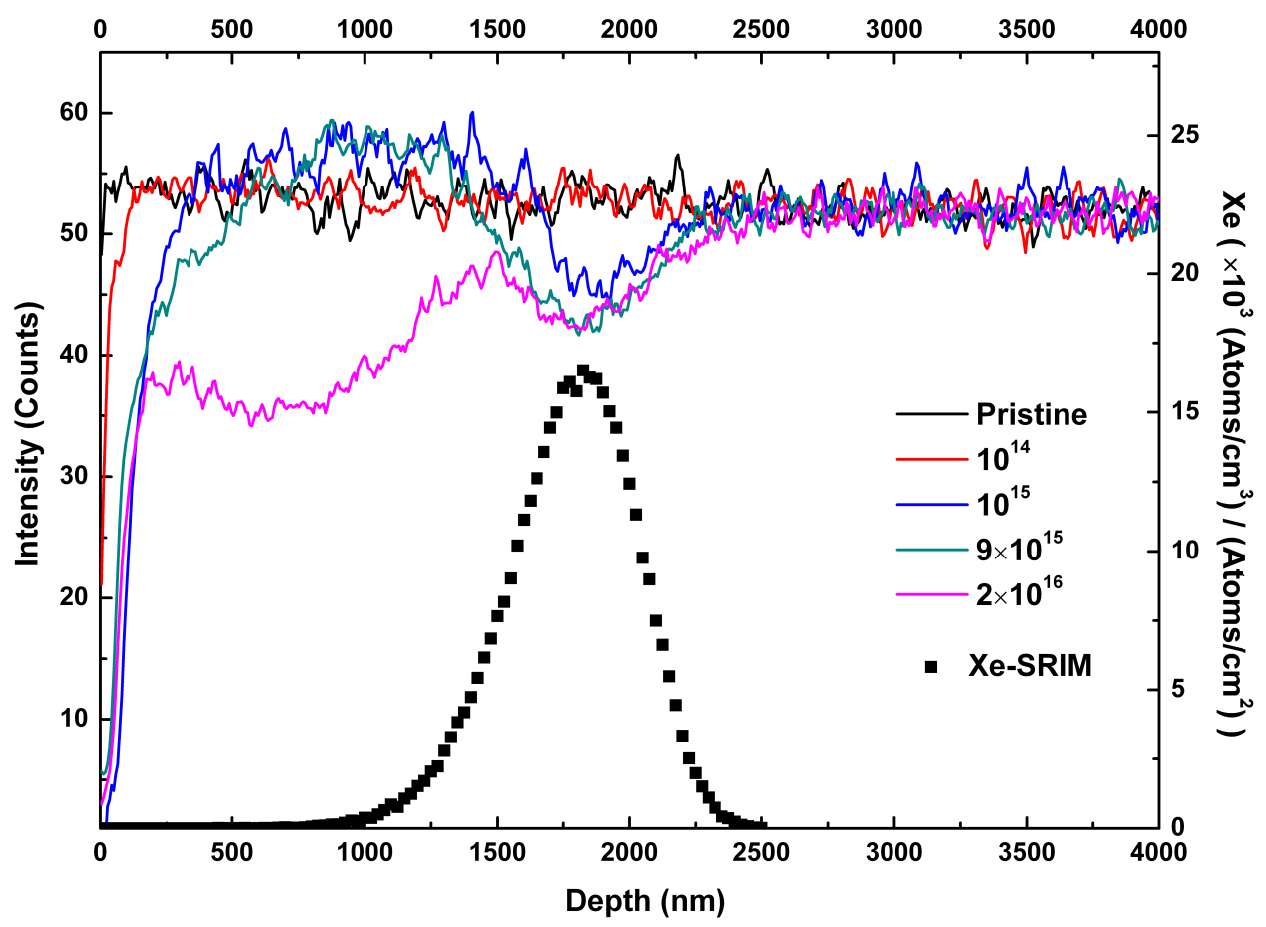

Fig. 6 


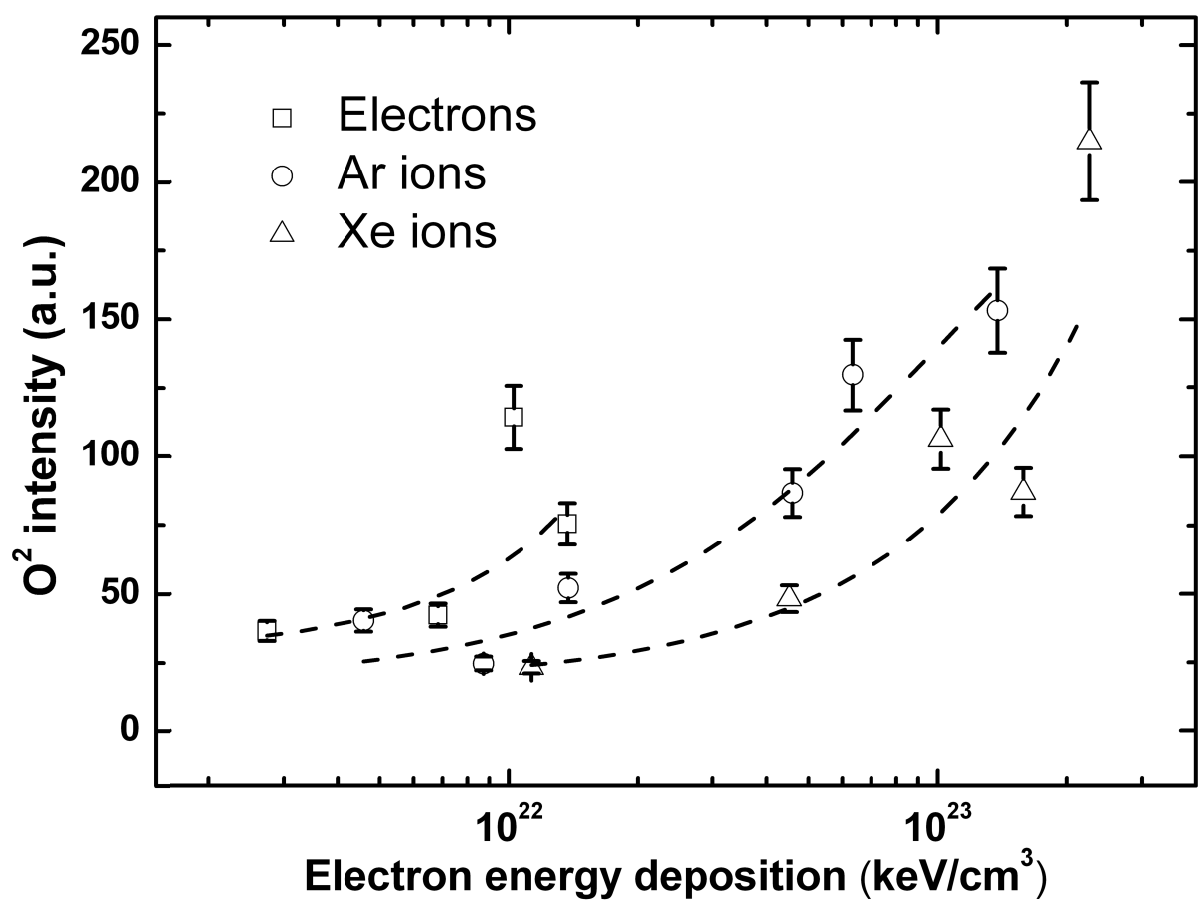

Fig. 7 